\title{
The apelinergic system as an alternative to catecholamines in low-output septic shock
}

\author{
David Coquerel ${ }^{1}$, Xavier Sainsily ${ }^{2,4}$, Lauralyne Dumont ${ }^{1,2,3}$, Philippe Sarret ${ }^{3,4}$, Éric Marsault ${ }^{3,4}$, \\ Mannix Auger-Messier ${ }^{2}$ and Olivier Lesur ${ }^{1,4^{*}}$
}

\begin{abstract}
Catecholamines, in concert with fluid resuscitation, have long been recommended in the management of septic shock. However, not all patients respond positively and controversy surrounding the efficacyto-safety profile of catecholamines has emerged, trending toward decatecholaminization. Contextually, it is time to re-examine the "maintaining blood pressure" paradigm by identifying safer and life-saving alternatives. We put in perspective the emerging and growing knowledge on a promising alternative avenue: the apelinergic system. This target exhibits invaluable pleiotropic properties, including inodilator activity, cardio-renal protection, and control of fluid homeostasis. Taken together, its effects are expected to be greatly beneficial for patients in septic shock.

Keywords: Apelinergic system, Apelin (APJ) receptor, Biased signaling, Decatecholaminization, Inodilator, Septic shock
\end{abstract}

Septic shock is a life-threatening condition initiated by an acute systemic inflammation with unbalanced host responses to microbial infection [1]. Persistent hypotension related to generalized vasodilation, refractory constrictive responsiveness, huge plasma capillary leak syndrome, coagulation/fibrinolysis imbalance, and metabolic disturbance highlighted by elevated bloodstream lactates are hallmarks of worst outcome in this critical condition [2]. Indeed, an alarming multiple organ failure (MOF) occurrence, aggravated by sustained low blood pressure/perfusion, is closely associated with high

\footnotetext{
* Correspondence: Olivier.Lesur@USherbrooke.ca

${ }^{1}$ Division of Intensive Care Units, Department of Medicine, Université de Sherbrooke, 3001 - 12e Avenue Nord, Sherbrooke, QC J1H 5 N4, Canada ${ }^{4}$ Pharmacology Institute of Sherbrooke, Faculty of Medecine and Health Sciences, Université de Sherbrooke, Sherbrooke, Québec, Canada Full list of author information is available at the end of the article
}

morbidity, long-term sequelae, and elevated mortality in septic shock [3].

Preventing insufficient blood delivery to tissues is rapidly recommended as a first-line treatment of septic shock after time-limited fluid resuscitation [2, 4]. This mandates the administration of catecholamine vasopressors such as norepinephrine (NE), a predominantly selective $\alpha$-adrenergic receptor $(\alpha-A R)$ agonist [4]. Importantly, hemodynamics bedside assessment reveals a high prevalence of myocardial dysfunction which can be detected early in up to $60 \%$ of septic patients [5]. In such cases, when cardiac output remains low despite fluid resuscitation (defined per se as a low-output septic shock), additional stimulation of the $\beta$-adrenergic receptor $(\beta-A R)$ by administration of dobutamine is suggested as a strong positive ino-/chronotrope drug [4]. However, whether recommended or only attempted, refractoriness of cardiac response to dobutamine is common in lowoutput septic shock, which negatively affects treatment efficacy and critically impacts survival, with increased mortality rates of up to $90 \%[6,7]$. Thus, can we do better than dobutamine? Yes, indeed, provided that lessons taught by history are remembered [8].

In this respect, alternative therapies with better potency/efficacy, less undesired effects, and improved vaso-/cardio-protective impact are urgently needed. The endogenous apelinergic system has recently emerged as a compelling target to sustain cardiovascular function in shock. Indeed, cardiac contractility and vascular tone, fluid homeostasis and kidney function, as well as energy metabolism, inflammatory response, and thrombosis are all physiological hallmarks impacted by apelin receptor (APJ) engagement (Fig. 1) [9-12]. Collectively, the above effects would be beneficial in septic shock and related conditions, with potential added value for outcome. Considering the proven "druggability" of G-proteincoupled receptors (GPCRs) and existing preclinical data, we outline the promising therapeutic potential of the apelinergic system in critically ill septic patients, with a 


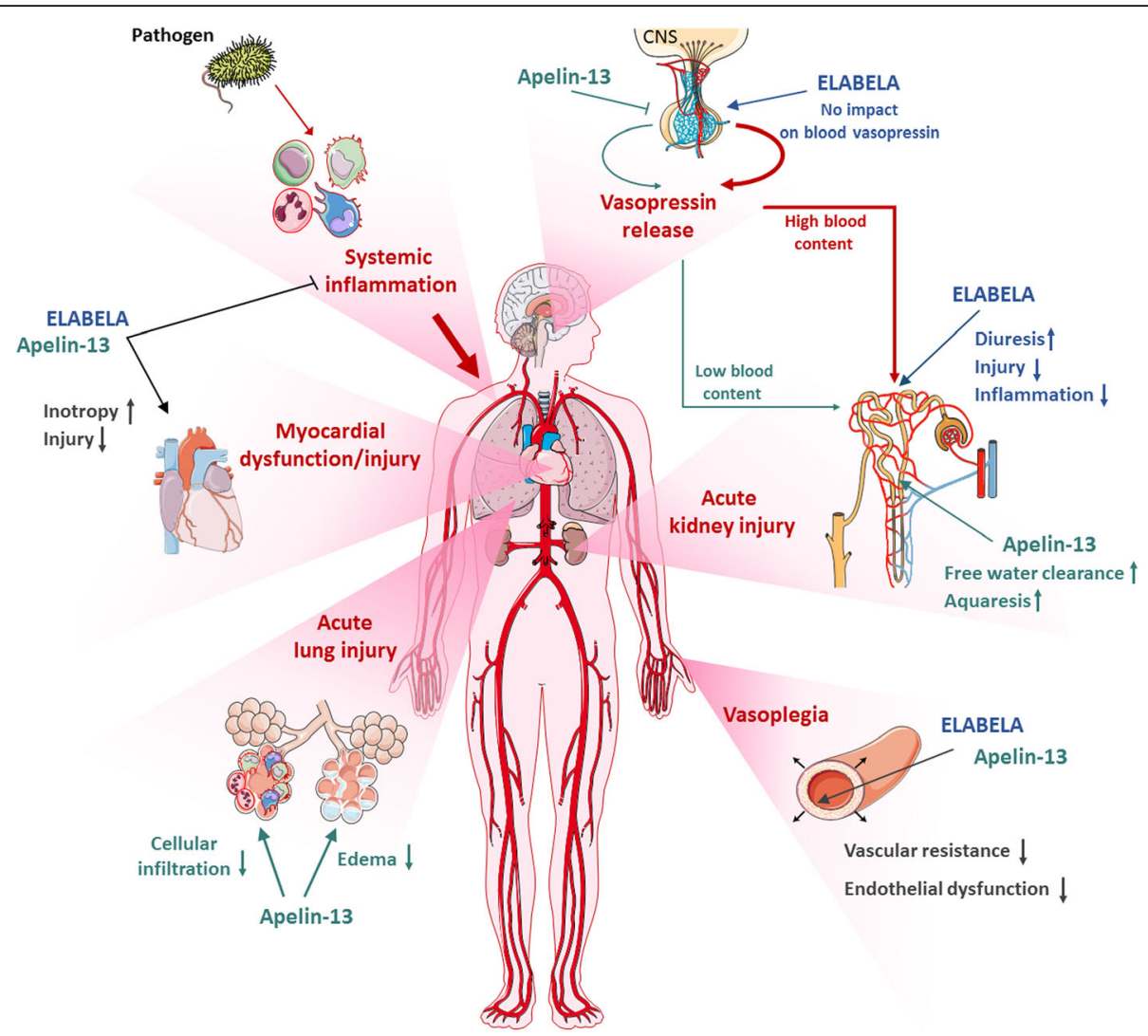

Fig. 1 Potential impacts of modulating the apelinergic system in human septic shock with multi-organ failure (MOF). Acute and continuous infusions of the endogenous apelin receptor (APJ) ligands Apelin-13 (APLN-13) and Eleabela (ELA) display several beneficial effects in preclinical septic shock (i.e., endotoxin and cecal ligation and puncture models) as well as in sepsis-related organ failure. Both APLN-13 and ELA reduce bloodstream and tissue inflammation, improve cardiovascular hemodynamics (e.g., enhanced inotropy, reduced pre- and after-load, as well as vascular permeability) and enhance diuresis. Specifically, APLN-13 and ELA exhibit a differential interplay with the vasopressinergic system and therefore modulate fluid homeostasis. APLN-13 alleviates pituitary AVP release, thus inducing low blood AVP and enhanced aquaresis. In contrast, ELA stimulates diuresis in a pressure- and kidney-dependent manner without modified blood AVP, preserving functional water reabsorption and contributing to enhanced plasma volume. Both APLN-13 and ELA infusions confer tissue protection and contribute to reduced mortality and improved outcomes in experimental septic shock. Inhibition of platelet function has been recently described as a novel property of APLN-13, potentially relevant to septic shock, but not addressed in this perspective. CNS central nervous system

focus on the stabilization of failing cardiovascular hemodynamics and kidney function.

\section{The need for decatecholaminization of critically ill patients}

Although useful vaso-/cardio-active agents to manage septic shock, catecholamines increase oxidative stress, interfere with cellular energy metabolism, disturb immunological response, and thus undermine their therapeutic value, sometimes exacerbating pre-existing myocardial dysfunction in sepsis $[6,13,14]$. Moreover, important endogenous fractions of mostly inefficient/oxidized circulating catecholamines combined with desensitized $\beta$-AR contribute to the hyporesponsiveness of cardiovascular sympathetic activation in septic shock [15-17]. Consequential excessive exogenous catecholamines (including dobutamine) are used to increase cardiac index, often without tangible benefits yet with exacerbated side effects and worse outcomes [18]. Interestingly, despite almost half a century of dobutamine use, $\beta$-blocking the septic heart is now proposed for cardioprotection, with recent evidence of the feasibility and effectiveness at both preclinical and clinical levels $[19,20]$. Thus, rather than searching for a catecholamine with the best pharmacological properties, a new paradigm called "decatecholaminization" is proposed to partially or completely spare exogenous catecholamine use $[21,22]$. Nonetheless, administering $\beta$-blockers is not the only way to achieve cardiovascular protection, and other non-adrenergic pathways hold great potential toward such a goal (Fig. 2).

In this context, GPCRs are attractive targets for the development of new drugs with beneficial cardiovascular effects on sepsis. For instance, engagement of the 


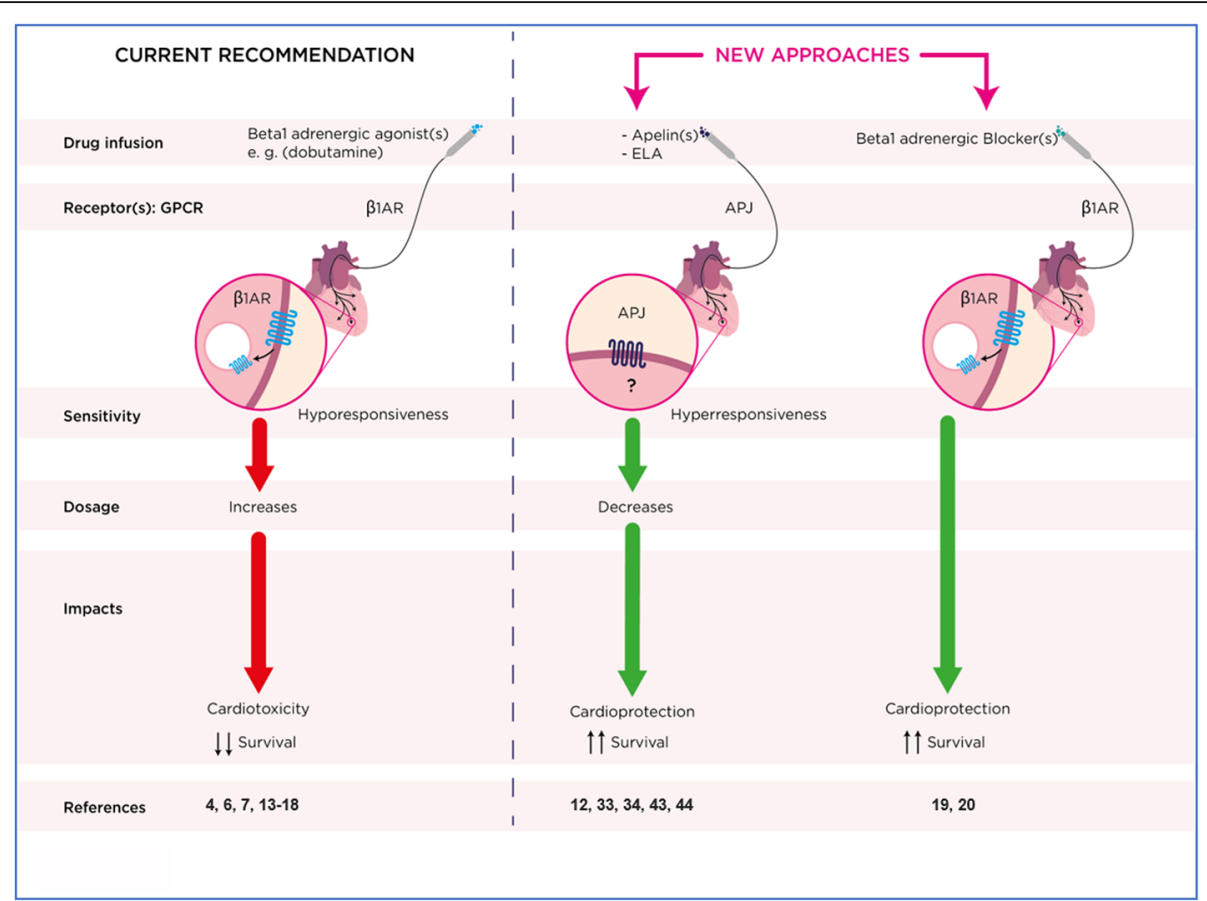

Fig. 2 Hemodynamic drug support in septic shock-related myocardial dysfunction: pharmacological state-of-the-art evidence and new approach concepts. Current recommendations after optimal fluid resuscitation are the introduction of adrenergic agonists with emphasis on the $\beta 1$ AR agonist dobutamine when cardiac index remains low, and somewhat often a hyporesponsiveness/increased dosage profile along with $\beta 1$ AR myocardial down-regulation. In spite of this decreased AR availability, cardioprotection and improved survival have been obtained with $\beta 1$ AR blockade. Apelinergic agonists offer cardioprotection and improved outcomes with a high responsiveness/dosage profile at the pre-clinical side. References supporting assumptions are cited in the text. ELA Eleabela

vascular arginine vasopressin (AVP) receptor $\mathrm{V}_{1 \mathrm{~A}}$ represents a potential target in septic shock [23]. Indeed, low-dose AVP infusion is helpful to restore vascular tone, with catecholamine-sparing ability in septic patients, and additional beneficial effects have been observed with selepressin (a selective $\mathrm{V}_{1 \mathrm{~A}}$ receptor agonist) in both a relevant preclinical model of sepsis and septic shock patients [24, 25]. Targeting the angiotensin system could also be beneficial in patients with NE-refractory shock, by acting on the angiotensin II (Ang II) type 1 receptor $\left(\mathrm{AT}_{1}\right.$ receptor), another GPCR with strong vasopressor activity [26]. However, AVP, Ang II, and all their derivatives are pure vasopressors without obvious direct supportive impact on the failing heart but result in potential inappropriate increased myocardial workload and, moreover, have significant drawbacks in unselected patients. With these considerations in mind, our group recently hypothesized that the inodilator properties (i.e., positive inotropic and vasodilator effects) of the apelinergic system might offer superior therapeutic value, compared to the standard of care, for the treatment of low-output septic shock. By combining those aforementioned capacities, apelinergic agonists would improve arterial-ventricular couplings and overall cardiac index delivery as well as organ perfusion.

\section{Functional and protective cardiovascular impacts of the apelinergic system}

An unknown receptor sharing high sequence homology with the angiotensin II type 1 receptor $\left(\mathrm{AT}_{1}\right)$ gene was identified in 1993 and denominated APJ (Apelin Peptide Jejunum) [27]. This novel receptor, not activated by Ang II, remained an "orphan" GPCR until 1998, when a peptide isolated from bovine stomach homogenates was identified as a selective ligand [28]. APJ is expressed by a wide range of eukaryotic cells and is prevalent in the central nervous system and peripheral organs, including lung, heart, vasculature, and kidney [29]. APJ activation is essentially triggered by two distinct endogenous peptides, i) apelins (APLNs) and ii) the recently discovered (in 2013) ELABELA (ELA; also known as Toddler or Apela) (Fig. 2). APLNs are members of the neuropeptide/adipokine families, and are physiological regulators of cardiovascular function, fluid homeostasis, and energy metabolism $[9,10]$. Mature endogenous APLNs-apelin36, apelin-17, and apelin-13 (APLN-13)-possess overlapping bioactive properties, but APLN-13 is the dominant isoform detected in human heart, vessels, and bloodstream [30, 31]. Physiologically, APLNs increase cardiac contractility in isolated hearts with equivalent efficiency to isoproterenol but with a much more 
sustained action through activation of protein kinase $\mathrm{C} \varepsilon$ and extracellular signal-regulated kinase $1 / 2$ signaling pathways [32]. Additionally, myosin long-chain kinase activation represents a downstream mechanism by which APLNs could sensitize cardiac myofilaments to $\mathrm{Ca}^{2+}$ [30]. Increased cardiomyocyte cytosolic $\mathrm{pH}$ and intracellular $\mathrm{Ca}^{2+}$ content through sodium hydrogen (NHE) and sodium calcium (NCX) exchanger activation have also been suggested to be involved in APLNdependent stimulation of cardiomyocyte contractility [33]. Lastly, APLN-dependent dromotropic effects through sodium channel (INa) activation may potentially confer antiarrhythmic abilities [34]. In vivo hemodynamic impacts of APLNs (e.g., induced nitric oxide-dependent and -independent decline in systemic vascular resistance and after load; increased loadindependent myocardial contractility and enhanced cardiac index and stroke volume) were confirmed both in preclinical models $[35,36]$ and at the bedside in humans [37]. Thus, APLNs are clearly members of the "inodilator" family.

ELA, on the other hand, is a long peptide that also activates APJ with similar binding affinity to APLNs [38]. First identified in a "noncoding" DNA region and then ignored, ELA is a potent regulator of early cardiac development in zebrafish [39]. ELA is highly expressed in undifferentiated human embryonic stem cells [40] and kidney [41], and has restricted expression in endothelial cells of adult human vessels [42]. Very recently, an early ELA defect was closely linked to hypertension-related preeclampsia [43]. Beyond its role in development, the ELA/APJ signaling axis is effective in promoting angiogenesis and counteracting Ang II production in adult rodents [44].

Recent results from our group and others demonstrated that exogenous delivery of APLN-13 is beneficial in experimental models of sepsis (e.g., endotoxemia, peritonitis, burns), reducing MOF and improving outcomes [12, 45, 46]. In fact, circulating and myocardial APLN-13 levels are low or weakly reactive in experimental sepsis and septic shock patients [47]. Compared to dobutamine continuous infusion, APLN-13 significantly increases survival and robustly improves left ventricular performance with reduced inflammation and stress [45]. Furthermore, APJ blockade exacerbates myocardial dysfunction and mortality in endotoxin-challenged rats, suggesting that the endogenous apelin system does contribute to counteracting life-threatening hemodynamic alterations [45]. ELA is also powerful and stronger than APLN-13 in stimulating healthy isolated hearts and improving hemodynamics in rats with peritonitis. This superior in vivo inotropic impact of ELA over APLN-13 was confirmed by others [41], including in right hearts with pulmonary arterial hypertension (PAH) [42]. In addition, continuous ELA infusion drives beneficial outcomes over APLN-13 and optimizes pressure-volume relationships of the Frank-Starling curve in a volumedependent manner [12]. This later observation seems attributable to a differential interplay between APLN-13 and ELA with the vasopressinergic system in the regulation of kidney water reabsorption. Reduction of circulating levels of pro-inflammatory cytokines induced by APLN-13 and ELA also contributes, reducing myocardial injury and systemic vascular permeability, with preserved plasma volume and hemodynamics [12]. Importantly, while sepsis dampens myocardial responsiveness to $\beta 1 \mathrm{AR}$ agonists, the apelinergic potency on the cardiac response is boosted under systemic inflammatory conditions [45] or polymicrobial infection [12], thus increasing its potential as a therapeutic target (Fig. 2).

\section{The apelinergic system in fluid homeostasis and renal failure}

Body fluid homeostasis is another important physiological role of the apelinergic system that would be beneficial in the management of the septic condition [9]. This system regulates both diuresis and thirst [48], and both APLN-13 and ELA stimulate urinary output and water intake [12]. Conversely, an abnormal fluid balance was observed in APJ-null mice [49]. APLN-13 enhances urinary output through direct and specific vasodilation of efferent renal arterioles, and the expression of APJ in collecting ducts further suggests aquaretic functions, reflecting an APLN-driven specific interplay with the vasopressinergic system [50]. Indeed, AVP binding to $\mathrm{V}_{2}$ receptors activates $\mathrm{G \alpha}_{\mathrm{s}}$-mediated adenylyl cyclase activity and leads to aquaporin 2 (AQP2) apical docking, driving water reabsorption and decreased diuresis. Activation of APJ coupled to $G \alpha_{i}$ counterbalances the action of AVP, preventing AQP2 membrane re-localization through adenylyl-cyclase inhibition [50]. APLNs also act in the central nervous system, inhibiting AVP neuron activity and consequent pituitary release in the bloodstream, with increasing aquaresis [48].

During experimental sepsis, whereas continuous infusion of APLN-13 or ELA both restore hemodynamics, only ELA is effective in reducing kidney dysfunction/injury and significantly improves fluid homeostasis, thus limiting hypovolemia [12]. Indeed, APLN-13 infusion lowers blood AVP levels in rats with peritonitis and tilts urinary balance toward undesired aquaresis with subsequent plasma volume loss. Conversely, ELA, which overall shares APLNs' physiological effects, does not modify blood AVP content and improves fluid balance through preserved AVP-dependent renal water reabsorption. Moreover, ELA reduces sepsis-induced kidney acute injury and inflammation compared to APLN-13 [12]. Such 
observation is consistent with the exhaustion of AVP release observed in human sepsis, which is suspected to promote sustained hemodynamic failure and immune dysfunction [51, 52]. Indeed, AVP supply affords a noncatecholaminergic pathway to limit hypotension in patients with septic shock [23]. These findings indicate that ELA and APLN-13 differentially affect the cardio-renal axis, mainly through opposing effects on vasopressinergic system counter-regulation, especially on an AVPdriven pathway, which could be centrally mediated and possibly related to the existence of an alternative cellsurface receptor yet to be discovered [40], or to distinct cellular outcomes of ELA binding to APJ.

This opens a wider discussion on the opportunity to optimize biased apelinergic agonists by modulating their structure-signaling relationship, with the final objective of selecting molecules specific for individualized clinical phenotypes.

\section{Potential of biased apelinergic agonists to improve hemodynamic support in septic shock}

During the past decade, advances in APLN research have revealed a ligand-dependent physiological response, suggesting several signaling pathways downstream of APJ. Traditionally, GPCR activation was considered to stimulate indiscriminately both $G$ protein-dependent and -independent pathways, irrespective of ligand structure (Fig. 3) [53]. However, some ligands can selectively activate favorable pathways and/or block the contribution of undesirable ones, leading to the concept of drugs targeting GPCRs (Fig. 3) [54]. It can be harnessed advantageously, through drug design and structural modifications, to primarily trigger desired cellular outcomes in the hope of significantly improving risk/benefit ratios in pathophysiological conditions. Indeed, previous studies have already demonstrated the value of targeting the apelinergic system in cardiovascular processes such as heart failure, leading to the discovery of biased APJ agonists [55].

According to current knowledge, canonical APJ signaling involves $\mathrm{G \alpha}_{\mathrm{i}}$ activation after stimulation by APLNs, leading to inhibition of adenylyl cyclase, decreased intracellular cAMP, and subsequent physiological effects [28]. As mentioned above, a specific interplay between natural apelinergic agonists (e.g., APLN-13 vs ELA) and the vasopressinergic system could induce distinct $\mathrm{APJ} / \mathrm{G \alpha}_{\mathrm{i}^{-}}$ driven outcomes on fluid balance and renal or cardiac functions during experimental sepsis. APJ activation also commits scaffolding proteins $\beta$-arrestins, which typically promote receptor internalization and initiate G-proteinindependent signaling cascades [56]. Interestingly, $\beta$ arrestin signaling has beneficial properties with regard to inhibiting sepsis-related inflammatory response [57]. Furthermore, $\beta$-arrestin overexpression dramatically attenuates sepsis-induced myocardial dysfunction [58].

Consistent with these experimental data, our group is currently elucidating the structure-activity relationship of APLNs and ELA, providing insight into binding and signaling to discover novel APJ biased ligands [38]. Overall, biased compounds are critical tools to improve

\section{a Classical view of GPCR signaling}

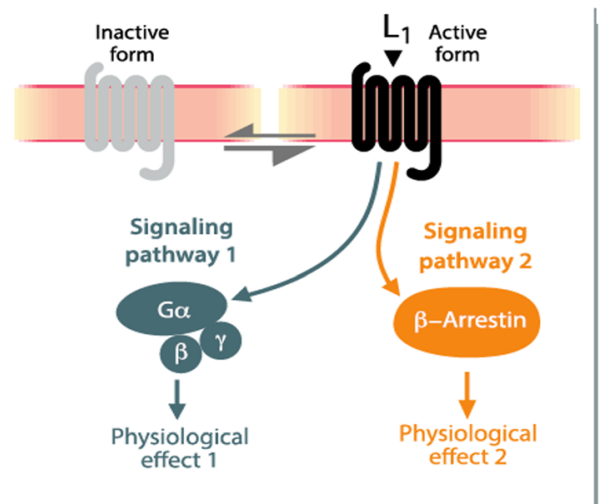

b Biased ligand signaling as a new concept in GPCR pharmacology

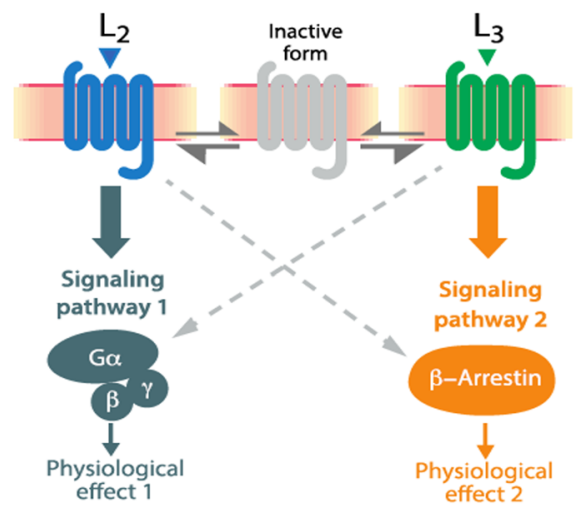

Fig. 3 The concept of biased signaling. a) In the classic model, ligand L1 binds and elicits a set of signaling pathways leading indiscriminately to multiple physiological effects. b) In biased signaling, ligand L2 biases the receptor toward signaling pathway 1, whereas ligand L3 induces bias for pathway 2, leading to distinct physiological outcomes

biased signaling. Fundamentally, this concept (i.e., functional selectivity) adds an additional layer of complexity to our understanding of the pharmacological action of the understanding of APJ-mediated cellular processes and their physiological consequences. Ultimately, those with advantageous effect(s) or devoid of undesirable 
effects and associated with specific signaling pathways can be selected and trialed in sepsis or any other indication potentially associated with GPCR targets. To date, the jury is still out and investigations to associate APJ signaling with in vivo phenotypic cardiovascular and renal functions is a conundrum that will have to be solved with the help of biased agonists demonstrating beneficial therapeutic impacts and reduced undesired activities in sepsis.

\section{Conclusions}

After its "first-in human" pilot study, the apelinergic system recently gained credibility at both the preclinical and early clinical stages as a potential therapeutic in chronic heart failure. Although exhibiting enriched pleiotropic abilities, recent evidence supports its protective impact on the cardiovascular and renal axes, which are prevalently compromised in septic shock with an acute myocardial dysfunction. Further knowledge and the development of dedicated biased agonists are ongoing and mandatory to bring to the market a new family of apelinergic drugs able to substitute for catecholamines in the treatment of sepsis.

\section{Abbreviations \\ a-AR: Alpha-adrenergic receptor; $\beta$-AR: Beta-adrenergic receptor; Ang II: Angiotensin II; APJ: Apelin peptide jejunum (apelin receptor); APLN: Apelin; AQP2: Aquaporin 2; AT1 receptor: Angiotensin II type 1 receptor; AVP: Arginine vasopressin; CAMP: Cyclic adenosine monophosphate; ELA: ELABELA; GPCR: G-protein coupled receptor; Ina: Sodium channel; MOF: Multiple organ failure; NE: Norepinephrine; NHE: Sodium hydrogen exchanger; NCX: Sodium calcium exchanger; PAH: Pulmonary arterial hypertension}

\section{Acknowledgements}

The authors thank Frederic Chagnon for his contribution.

\section{Funding}

Supported by: Merck-Sharp-Dohme FMSS, Mitacs (IT05862, IT08045), PAFICRCHUS, SEP-NSERC (EGP488509-15) grants, Canadian Institutes of Health Research (CIHR \# 376770).

\section{Availability of supporting data}

Not applicable.

\section{Authors' contributions}

DC, XS, LD, and OL drafted the initial manuscript; PS, ÉM, and MA-M provided expertise in the field of ligand-receptor pharmacology, structure-activity relationships, and cardiovascular signaling mechanisms, respectively. OL conceived the concept underlying the manuscript and is the senior author of the paper. All authors were involved in writing and editing the manuscript, including the figures, and read and approved the final version.

\section{Authors' information}

Not applicable.

Ethics approval and consent to participate

Not applicable.

Consent for publication

Not applicable.

\section{Competing interests}

The authors declare that they have no competing interests.

\section{Publisher's Note}

Springer Nature remains neutral with regard to jurisdictional claims in published maps and institutional affiliations.

\section{Author details}

${ }^{1}$ Division of Intensive Care Units, Department of Medicine, Université de Sherbrooke, 3001 - 12e Avenue Nord, Sherbrooke, QC J1H 5 N4, Canada. ${ }^{2}$ Division of Cardiology, Department of Medicine, Université de Sherbrooke, Sherbrooke, Québec, Canada. ${ }^{3}$ Department of Pharmacology-Physiology, Université de Sherbrooke, Sherbrooke, Québec, Canada. ${ }^{4}$ Pharmacology Institute of Sherbrooke, Faculty of Medecine and Health Sciences, Université de Sherbrooke, Sherbrooke, Québec, Canada.

Received: 7 November 2017 Accepted: 3 January 2018

Published online: 19 January 2018

\section{References}

1. van der Poll T, van de Veerdonk FL, Scicluna BP, Netea MG. The immunopathology of sepsis and potential therapeutic targets. Nat Rev Immunol. 2017:17:407-20.

2. Annane D, Bellissant E, Cavaillon JM. Septic shock. Lancet. 2005;365:63-78.

3. Gaieski DF, Edwards JM, Kallan MJ, Carr BG. Benchmarking the incidence and mortality of severe sepsis in the United States. Crit Care Med. 2013;41: 1167-74.

4. Rhodes A, Evans LE, Alhazzani W, Levy MM, Antonelli M, Ferrer R, et al. Surviving Sepsis Campaign: international guidelines for management of sepsis and septic shock: 2016. Crit Care Med. 2017:45:486-552.

5. Vieillard-Baron A, Caille V, Charron C, Belliard G, Page B, Jardin F. Actual incidence of global left ventricular hypokinesia in adult septic shock. Crit Care Med. 2008;36:1701-6.

6. Kumar A, Schupp E, Bunnell E, Ali A, Milcarek B, Parrillo JE. Cardiovascular response to dobutamine stress predicts outcome in severe sepsis and septic shock. Crit Care. 2008:12:R35.

7. Cariou A, Pinsky MR, Monchi M, Laurent I, Vinsonneau C, Chiche JD, et al. Is myocardial adrenergic responsiveness depressed in human septic shock? Intensive Care Med. 2008:34:917-22.

8. McNally EM. Can we do better than dobutamine? Circ Res. 2013;113:355-7.

9. Galanth C, Hus-Citharel A, Li B, Llorens-Cortes C. Apelin in the control of body fluid homeostasis and cardiovascular functions. Curr Pharm Des. 2012; 18:789-98.

10. Bertrand C, Valet P, Castan-Laurell I. Apelin and energy metabolism. Front Physiol. 2015:6:115.

11. Adam F, Khatib AM, Lopez JJ, Vatier C, Turpin S, Muscat A, et al. Apelin: an antithrombotic factor that inhibits platelet function. Blood. 2016;127:908-20.

12. Coquerel D, Chagnon F, Sainsily X, Dumont L, Murza A, Cote J, et al. ELABELA improves cardio-renal outcome in fatal experimental septic shock. Crit Care Med. 2017;45:e1139-48.

13. Schmittinger CA, Torgersen C, Luckner G, Schroder DC, Lorenz I, Dunser MW. Adverse cardiac events during catecholamine vasopressor therapy: a prospective observational study. Intensive Care Med. 2012;38:950-8.

14. Hartmann C, Radermacher P, Wepler M, Nubaum B. Non-hemodynamic effects of catecholamines. Shock. 2017:40:390-400.

15. de Montmollin E, Aboab J, Mansart A, Annane D. Bench-to-bedside review: Beta-adrenergic modulation in sepsis. Crit Care. 2009;13:230.

16. Silverman HJ, Penaranda R, Orens JB, Lee NH. Impaired beta-adrenergic receptor stimulation of cyclic adenosine monophosphate in human septic shock: association with myocardial hyporesponsiveness to catecholamines. Crit Care Med. 1993;21:31-9.

17. Macarthur H, Westfall TC, Riley DP, Misko TP, Salvemini D. Inactivation of catecholamines by superoxide gives new insights on the pathogenesis of septic shock. Proc Natl Acad Sci U S A. 2000;97:9753-8.

18. Auchet T, Regnier MA, Girerd N, Levy B. Outcome of patients with septic shock and high-dose vasopressor therapy. Ann Intensive Care. 2017;7:43,

19. Morelli A, Ertmer C, Westphal M, Rehberg S, Kampmeier T, Ligges S, et al. Effect of heart rate control with esmolol on hemodynamic and clinical outcomes in patients with septic shock a randomized clinical trial. JAMA. 2013;310:1683-91. 
20. Kimmoun A, Louis H, Al Kattani N, Delemazure J, Dessales N, Wei C, et al. beta1-Adrenergic inhibition improves cardiac and vascular function in experimental septic shock. Crit Care Med. 2015;43:e332-40.

21. Asfar P, Russell JA, Tuckermann J, Radermacher P. Selepressin in septic shock: a step toward decatecholaminization? Crit Care Med. 2016;44:234-6.

22. Rudiger A. Beta-block the septic heart. Crit Care Med. 2010;3(Suppl):S608-12.

23. Russell JA, Walley KR, Singer J, Gordon AC, Hebert PC, Cooper DJ, et al. Vasopressin versus norepinephrine infusion in patients with septic shock. $N$ Engl J Med. 2008;358:877-87

24. He X, Su F, Taccone FS, Laporte R, Kjolbye AL, Zhang J, et al. A selective $V(1 A)$ receptor agonist, selepressin, is superior to arginine vasopressin and to norepinephrine in ovine septic shock. Crit Care Med. 2016;44:23-31.

25. Russell JA, Vincent $J L$, Kjolbye AL, Olsson $H$, Blemings A, Spapen $H$, et al. Selepressin, a novel selective vasopressin V1A agonist, is an effective substitute for norepinephrine in a phase lla randomized, placebo-controlled trial in septic shock patients. Crit Care. 2017;21:213.

26. Khanna A, English SW, Wang XS, Ham K, Tumlin J, Szerlip H, et al. Angiotensin II for the treatment of vasodilatory shock. N Engl J Med. 2017 377:419-30.

27. O'Dowd BF, Heiber M, Chan A, Heng HH, Tsui LC, Kennedy JL, et al. A human gene that shows identity with the gene encoding the angiotensin receptor is located on chromosome 11. Gene. 1993;136(1-2):355-60.

28. Habata Y, Fujii R, Hosoya M, Fukusumi S, Kawamata Y, Hinuma S, et al. Apelin, the natural ligand of the orphan receptor APJ, is abundantly secreted in the colostrum. Biochim Biophys Acta. 1999:1452(1):25-35.

29. Hosoya M, Kawamata Y, Fukusumi S, Fujii R, Habata Y, Hinuma S, et al. Molecular and functional characteristics of APJ. Tissue distribution of mRNA and interaction with the endogenous ligand apelin. J Biol Chem. 2000;275: 21061-7.

30. Maguire JJ, Kleinz MJ, Pitkin SL, Davenport AP. [Pyr1]apelin-13 identified as the predominant apelin isoform in the human heart: vasoactive mechanisms and inotropic action in disease. Hypertension 2009:54:598-604.

31. Zhen EY, Higgs RE, Gutierrez JA. Pyroglutamyl apelin-13 identified as the major apelin isoform in human plasma. Anal Biochem. 2013;442:1-9.

32. Perjes A, Skoumal $R$, Tenhunen $O$, Konyi A, Simon M, Horvath IG, et al. Apelin increases cardiac contractility via protein kinase Cepsilon- and extracellular signal-regulated kinase-dependent mechanisms. PLoS One. 2014;9:e93473.

33. Wang C, Du JF, Wu F, Wang HC. Apelin decreases the SR Ca2+ content but enhances the amplitude of [Ca2+]i transient and contractions during twitches in isolated rat cardiac myocytes. Am J Physiol Heart Circ Physiol. 2008;294:H2540-6.

34. Chamberland C, Barajas-Martinez H, Haufe V, Fecteau MH, Delabre JF, Burashnikov A, et al. Modulation of canine cardiac sodium current by Apelin. J Mol Cell Cardiol. 2010;48:694-701.

35. Szokodi I, Tavi P, Foldes G, Voutilainen-Myllyla S, Ilves M, Tokola H, et al. Apelin, the novel endogenous ligand of the orphan receptor APJ, regulates cardiac contractility. Circ Res. 2002;91:434-40.

36. Ashley EA, Powers J, Chen M, Kundu R, Finsterbach T, Caffarelli A, et al. The endogenous peptide apelin potently improves cardiac contractility and reduces cardiac loading in vivo. Cardiovasc Res. 2005:65:73-82.

37. Japp AG, Cruden NL, Amer DA, Li VK, Goudie EB, Johnston NR, et al. Vascular effects of apelin in vivo in man. J Am Coll Cardiol. 2008:52:908-13.

38. Murza A, Sainsily X, Coquerel D, Cote J, Marx P, Besserer-Offroy E, et al. Discovery and structure-activity relationship of a bioactive fragment of ELABELA that modulates vascular and cardiac functions. J Med Chem. 2016; 59:2962-72.

39. Chng SC, Ho L, Tian J, Reversade B. ELABELA: a hormone essential for heart development signals via the apelin receptor. Dev Cell. 2013;27:672-80.

40. Ho L, Tan SY, Wee S, Wu Y, Tan SJ, Ramakrishna NB, et al. ELABELA is an endogenous growth factor that sustains hESC self-renewal via the PI3K/AKT pathway. Cell Stem Cell. 2015;17:435-47.

41. Perjes A, Kilpio T, Ulvila J, Magga J, Alakoski T, Szabo Z, et al. Characterization of apela, a novel endogenous ligand of apelin receptor, in the adult heart. Basic Res Cardiol. 2016;111:2

42. Yang P, Read C, Kuc RE, Buonincontri G, Southwood M, Torella R, et al. Elabela/Toddler is an endogenous agonist of the Apelin APJ receptor in the adult cardiovascular system, and exogenous administration of the peptide compensates for the downregulation of its expression in pulmonary arterial hypertension. Circulation. 2017;135:1160-73.
43. Ho L, van Dijk M, Chye STJ, Messerschmidt DM, Chng SC, Ong S, et al. ELABELA deficiency promotes preeclampsia and cardiovascular malformations in mice. Science. 2017;357:707-13.

44. Sato T, Sato C, Kadowaki A, Watanabe H, Ho L, Ishida J, et al. ELABELA-APJ axis protects from pressure overload heart failure and angiotensin IIinduced cardiac damage. Cardiovasc Res. 2017;113:760-9.

45. Chagnon F, Coquerel D, Salvail D, Marsault E, Dumaine R, Auger-Messier M, et al. Apelin compared with dobutamine exerts cardioprotection and extends survival in a rat model of endotoxin-induced myocardial dysfunction. Crit Care Med. 2016;45:e391-8.

46. Luo $\mathrm{K}$, Long $\mathrm{H}, \mathrm{Xu} \mathrm{B}$, Luo Y. Apelin attenuates postburn sepsis via a phosphatidylinositol 3-kinase/protein kinase B dependent mechanism: a randomized animal study. Int J Surg. 2015;21:22-7.

47. Lesur O, Roussy JF, Chagnon F, Gallo-Payet N, Dumaine R, Sarret P, et al. Proven infection-related sepsis induces a differential stress response early after ICU admission. Crit Care. 2010;14:R131.

48. De Mota N, Reaux-Le Goazigo A, El Messari S, Chartrel N, Roesch D, Dujardin C, et al. Apelin, a potent diuretic neuropeptide counteracting vasopressin actions through inhibition of vasopressin neuron activity and vasopressin release. Proc Natl Acad Sci U S A. 2004:101:10464-9.

49. Roberts EM, Newson MJ, Pope GR, Landgraf R, Lolait SJ, O'Carroll AM. Abnormal fluid homeostasis in apelin receptor knockout mice. J Endocrinol. 2009;202:453-62.

50. Hus-Citharel A, Bodineau L, Frugiere A, Joubert F, Bouby N, Llorens-Cortes C. Apelin counteracts vasopressin-induced water reabsorption via cross talk between apelin and vasopressin receptor signaling pathways in the rat collecting duct. Endocrinology. 2014;155:4483-93.

51. Russell JA, Walley KR. Vasopressin and its immune effects in septic shock. J Innate Immun. 2010;2:446-60.

52. Russell JA, Fjell C, Hsu JL, Lee T, Boyd J, Thair S, et al. Vasopressin compared with norepinephrine augments the decline of plasma cytokine levels in septic shock. Am J Respir Crit Care Med. 2013;188:356-64.

53. Pupo AS, Duarte DA, Lima V, Teixeira LB, Parreiras ESLT, Costa-Neto CM. Recent updates on GPCR biased agonism. Pharmacol Res. 2016;112:49-57.

54. Audet M, Bouvier M. Restructuring G-protein-coupled receptor activation. Cell. 2012;151:14-23.

55. Brame AL, Maguire JJ, Yang P, Dyson A, Torella R, Cheriyan J, et al. Design, characterization, and first-in-human study of the vascular actions of a novel biased apelin receptor agonist. Hypertension. 2015;65:834-40.

56. Gurevich W, Gurevich EV. Overview of different mechanisms of arrestinmediated signaling. Curr Protocols Pharmacol 2014;67:Unit 210 11-19.

57. Fan H, Bitto A, Zingarelli B, Luttrell LM, Borg K, Halushka PV, et al. Betaarrestin 2 negatively regulates sepsis-induced inflammation. Immunology. 2010:130:344-51.

58. Yan H, Li H, Denney J, Daniels C, Singh K, Chua B, et al. Beta-arrestin 2 attenuates cardiac dysfunction in polymicrobial sepsis through gp130 and p38. Biochem Biophys Rep. 2016;7:130-7.

\section{Submit your next manuscript to BioMed Central and we will help you at every step:}

- We accept pre-submission inquiries

- Our selector tool helps you to find the most relevant journal

- We provide round the clock customer support

- Convenient online submission

- Thorough peer review

- Inclusion in PubMed and all major indexing services

- Maximum visibility for your research

Submit your manuscript at www.biomedcentral.com/submit 